\title{
W JAKIM ZAKRESIE TŁUMACZ TEKSTÓW LITERACKICH Z JĘZYKA POLSKIEGO NA KASZUBSZCZYZNE JEST POŚREDNIKIEM MIĘDZY KULTURAMI?
}

DOI: http://dx.doi.org/10.12775/RP.2017.014

Zarys treści: Kultura kaszubska nie jest zupełnie odrębna od polskiej. Mimo przenikania się tych dwóch kultur można uznać, że tłumacz tekstów literackich z języka polskiego na kaszubski jest w pewnym zakresie pośrednikiem między kulturami. Nie będzie dla niego trudnością nazwanie realiów polskich, które znane są Kaszubom i językowi kaszubskiemu. Elementami kulturowymi, które mogą sprawić kaszubskiemu tłumaczowi problem, są właściwe kulturze polskiej związki frazeologiczne, a także realia kultur egzotycznych opisane w tekstach literackich polskojęzycznych.

Słowa kluczowe: kultura, język kaszubski, język polski, przekład literacki

0 bserwowane w przekładach literatury pięknej z języka polskiego na kaszubszczyznę problemy z przetłumaczeniem właściwych polszczyźnie elementów kulturowych nie są zbyt częste. Wynika to z faktu, że kultura kaszubska nie jest zupełnie odrębna od polskiej. Kaszuby znajdują się na terytorium Polski, natomiast Kaszubi stanowią część narodu polskiego i polskiej wspólnoty kulturowej. Kontakty kulturowe między Kaszubami a pozostałym obszarem Polski mają charakter stały i dokonują się od wielu wieków, stąd też kultura polska i kaszubska zazębiają się, przenikają i uzupełniają.

Tłumacz tekstów z języka polskiego na język kaszubski zwykle nie ma trudności z translacją nazw przedmiotów czy zjawisk występujących w kulturze polskiej. Takie problemy napotykają autorzy tłumaczeń literatury polskiej 
na języki właściwe narodom czy grupom etnicznym pochodzącym spoza obszaru Polski. Tymczasem realia polskiego życia, przedmioty charakterystyczne dla kultury polskiej zwykle mają swoje nazwy także w kaszubszczyźnie, a w sytuacji, gdy ich nie mają, zostają one skaszubione, czyli przystosowane do zasad fonetyki kaszubskiej i zapisane zgodnie $\mathrm{z}$ regułami ortograficznymi kaszubszczyzny. Mimo iż tłumacz kaszubski nie ma trudności z przekładem realiów polskich, nie można powiedzieć, że w żadnym stopniu nie jest on pośrednikiem między kulturami. Chociaż kultura kaszubska jest integralną częścią kultury polskiej, autor tłumaczeń na kaszubszczyznę również staje się pośrednikiem w transferze kultury (Krysztofiak 2011: 56-57).

Elementy nacechowane kulturowo są tymi składnikami, których przekład może sprawić trudność tłumaczowi tekstów z języka polskiego na kaszubski. Wśród tych elementów znajdują się przede wszystkim zakorzenione w kulturze polskiej związki frazeologiczne oraz przysłowia, które nie funkcjonują w kaszubszczyźnie. Dokonując ich translacji, tłumacz musi poszukiwać ekwiwalentów użytych zwrotów i wyrażeń w zasobach kulturowych języka kaszubskiego bądź też wyjaśnić ich sens w inny sposób. Jak już wspomniałam, realia życia polskiego zwykle nie stanowią problemu w procesie przekładu tekstu na kaszubszczyznę, jednakże problemem dla tłumacza kaszubskiego mogą być pojawiające się w polskich pierwowzorach nazwy przedmiotów i zjawisk typowych dla kultur innych niż polska. Autor translacji musi ustosunkować się do tych elementów nacechowanych kulturowo, które nie mieszczą się w obrębie tradycyjnej binarnej opozycji kultur, i jego zadaniem jest podjęcie dialogu międzykulturowego (Wolek-San Sebastian 2011: 13-14). Powinien on uporać się z tzw. elementami „trzeciej kultury”, czyli tymi składnikami tekstu oryginału i / lub przekładu, które są „obce zarówno w języku i kulturze oryginału, jak i w języku i kulturze przekładu" (Urbanek 2002: 61-69). Zaczerpnięte są one z kultur zewnętrznych zarówno w relacji do tekstu wyjściowego, jak i docelowego (Wolek-San Sebastian 2011: 7), natomiast autor tłumaczenia, który musi się do nich odnieść, występuje jako łącznik interkulturowy (Bednarczyk 2002). Problem z nazywaniem elementów „kultury trzeciej” miał tłumacz Sonetów krymskich Adama Mickiewicza, Stanisław Janke (Mickiewicz 2010).

W pierwszej kolejności przyjrzę się związkom frazeologicznym pojawiającym się w polskich pierwowzorach i sposobom ich translacji w literaturze kaszubskiej. Frazeologizmy są zawsze ugruntowane w kulturze danego języka i jako nierozdzielne całości niosą sens, którego nie da się logicznie wyprowadzić, analizując każdy element związku frazeologicznego oddzielnie. Przekład tego typu jednostek wymaga odkodowania informacji kulturowej 
w nich zawartych (Dąmbska-Prokop, red., 2000: 107-108). Gdy w pierwowzorze tłumaczonego tekstu zostanie odnotowana struktura frazeologiczna, zadaniem tłumacza jest znalezienie jej ekwiwalentu w języku docelowym. Walerij Mokijenko słusznie zwrócił uwagę, że w języku przekładu nie zawsze istnieje pełny ekwiwalent danego frazeologizmu, czasami mamy do czynienia z ekwiwalencją częściową lub konstrukcjami analogicznymi, w języku wyjściowym mogą także zostać użyte frazeologizmy, które w języku docelowym nie mają żadnych ekwiwalentów (Мокиенко 2014: 18-19). Tłumacz tekstów z języka polskiego na język kaszubski w tym sensie jest pośrednikiem między kulturami, że poszukuje w kaszubszczyźnie ekwiwalentów właściwych polszczyźnie połączeń frazeologicznych. Mimo bliskości językowej polszczyzny i języka kaszubskiego poszukiwanie odpowiedników związków frazeologicznych w języku docelowym wywołało wśród kaszubskich tłumaczy problemy. Polskie frazeologizmy, które sprawiły pewną trudność autorom przekładów na język kaszubski, znalazły się w tekstach Pana Tadeusza Adama Mickiewicza, w Trenach Jana Kochanowskiego, w wierszach Jana Brzechwy i Juliana Tuwima.

Tłumacz Pana Tadeusza na język kaszubski, Stanisław Janke, podczas pracy przekładowej wielokrotnie musiał szukać ekwiwalentów użytych w pierwowzorze frazeologizmów. W Księdze drugiej polskiej epopei narodowej mowa jest o tym, że Jacek Soplica zakochał się w córce Stolnika, Ewie, natomiast ojciec wybranki nie był przychylny wydaniu jej za Soplicę, z tego względu młodzieńcowi starającemu się o rękę Ewy podano czarną polewkę: „Już miał się oświadczyć, lecz pomiarkowano / I czarną mu polewkę do stołu podano” (Księga Druga, w. 281-282), „Soplicy Horeszkowie odmówili dziewkę! / Że mnie, Jackowi czarną podano polewkę!" (Księga Dziesiąta, w. 584-585). Czarna polewka to czernina - zupa z krwi kaczej; podanie jej do stołu w czasach szlacheckich oznaczało odmowę rodziców panny, dawaną starającemu się o jej rękę, bądź też odrzucenie mężczyzny przez samą pannę (Dubisz, Sobol 2005: 374). Dzisiaj obyczaj ten nie jest już żywy, jednakże zachował się frazeologizm podać komuś czarna polewkę w znaczeniu 'doświadczyć odmowy w konkurach'. Na obszarze kaszubskim niegdyś panował analogiczny zwyczaj - znakiem, że starania mężczyzny o rękę panny są daremne, było podanie podczas swatów gotowanej kaszy żytniej niezalanej mlekiem, która znana była na Kaszubach pod nazwą czôrné krëpë. Tradycja ta nie jest już praktykowana, jednakże w kaszubszczyźnie utrzymał się frazeologizm dac kòmùs czôrné krëpë (Sychta 1965-1976, II: 247). Powyższy związek frazeologiczny został użyty przez Stanisława Jankego w przekładzie na język kaszubski Pana Tadeusza: „I ju miôł sã òswiôdczëc, leno zmiarkòwelë / 
I jemù czôrné krëpë tak na stół pòdelë”. (Knéga Drëgô, w. 281-282), „Soplëcë Hòreszkòwie dac córczi nie chcelë! / Tak mie wej, Jacekòwi, czôrné krëpë delë!" (Dzesątô Knéga, w. 583-584).

W Księdze siódmej polskiego eposu opisana jest narada odbywająca się w domu Macieja. W jej trakcie Bartek mówił, że w podobny sposób jak Francja pokonała Prusy, teraz z Litwy należy pozbyć się Moskali. Maciej zaczął wypytywać Prusaka, skąd ma takie nowiny dotyczące wojsk francuskich. Ten odpowiedział mu, że wiadomości te pochodzą od bernardyna, księdza Robaka. Maciej twierdził, iż ksiądz Robak może być niewiarygodny, bo zdążył go poznać. Opowiadając o bernardynie, wypowiedział on następujące słowa: „Poznałem, co za ptaszek” (Księga siódma, w. 116). Zwrot poznałem, co to za ptaszek nie jest notowany przez słowniki frazeologiczne polszczyzny, jednakże funkcjonuje on w języku jako frazeologizm i odnosi się do 'osobnika podejrzanego, niebezpiecznego, którego należy się wystrzegać. W języku kaszubskim ekwiwalent polskiego wyrazu ptaszek - ptôszk - nie wywołuje takich konotacji, stąd też tłumacz napotkał tutaj problem podczas wykonywania translacji eposu. W kaszubskojęzycznym przekładzie powyższa fraza została przetłumaczona następująco: "jô pòznôł, co to za lësk" (Sódmô knéga, w. 116). W kaszubszczyźnie znane są powiedzenia: to je taczi lës (Gołąbek 2012-2013, II: 56) albo to je lës òd człowieka (Gołąbek 20122013, II: 56), które mają odnosić się do osoby przebiegłej, podejrzanej. Trzeba zwrócić uwagę, że wyraz lis ma podobne metaforyczne znaczenie także w polszczyźnie.

Niekiedy tłumaczowi Pana Tadeusza na język kaszubski nie udało się znaleźć $\mathrm{w}$ języku docelowym ekwiwalentu użytego $\mathrm{w}$ pierwowzorze frazeologizmu. W jednym przypadku Janke przetłumaczył związek frazeologiczny obecny w pierwowzorze poprzez wprowadzenie metafory, która dla czytelnika nieznającego polskiego oryginału jest niejasna, a którą sam autor przekładu w prywatnej rozmowie nazwał „własnym autorskim neofrazeologizmem". Bartek opowiadał o tym, jak z pomocą wojsk francuskich Bonapartego w 1806 roku zostali przepędzeni Prusacy z Wielkopolski. W toku tej opowieści pojawił się zwrot: „z hofratów drzeć schaby” (Księga siódma, w. 48). Hofraci byli to urzędnicy pruscy, natomiast frazeologizm drzeć $z$ kogoś schaby oznacza 'bić kogoś, okładać kogoś po plecach' (Dubisz, Sobol 2005: 95). W kaszubskojęzycznej translacji odpowiednikiem powyżej przytoczonej Mickiewiczowskiej frazy jest następujący zwrot: „hòfratów brac w kòpë” (Sódmô knéga, w. 48), który również ma odnosić się do bicia kogoś. Nie jest on notowany przez słowniki kaszubszczyzny i został stworzony przez tłumacza w celu użycia go w tym konkretnym tekście. 
W innym fragmencie autor tłumaczenia Pana Tadeusza wykorzystał opisową metodę wyjaśnienia użytego w języku wyjściowym związku frazeologicznego. W epopei opisano, jak rozgorzała kłótnia Asesora z Rejentem o to, czyj chart upolował zająca. Gdy miało dojść do rękoczynów, Wojski powiedział: „Szkoda ust dłużej suszyć kłótnią o zająca” (Księga druga, w. 806). W wypowiedzi tej pojawił się zwrot frazeologiczny suszyć usta, który oznacza 'mówić coś niepotrzebnie' (Górski, Hrabec 1962-1983: 415-419). Tłumacz, przekładając tę frazę na język kaszubski, wyeliminował przenośne znaczenie i ma ona następującą postać: „Ni ma ò co sã wadzëc, szkòda słów ò wrzoskù” (Drëgô knéga, w. 806).

Trudność z przetłumaczeniem na język kaszubski związku frazeologicznego napotkał też autor przekładu Trenów Jana Kochanowskiego - Janusz Mamelski (Kochanowski 2011). W Trenie I pojawił się archaiczny polski frazeologizm umyka pierza odnotowany w kontekście „A ta nieboga ledwe umyka pierza”. Czasownik umykać w staropolszczyźnie znaczył tyle, co 'cofać się, uchylać się, aby uniknąć zagrożenia' (Kucała 1994-2012, V: 255). Natomiast użyta przez Kochanowskiego fraza umyka pierza oznacza, że matka zmarłej dziewczynki ratuje się. Fraza ta w pierwotnym znaczeniu odnosiła się do ptaka i oznaczała, że ów ptak przez umknięcie ocala pierze, umyka wraz ze swoim pierzem, czyli uchodzi cało z niebezpieczeństwa (Kucała 1994-2012, III: 467) . W kaszubszczyźnie nie ma frazeologizmu o analogicznym znaczeniu, dlatego zwrot ten został przetłumaczony na język kaszubski opisowo: „swòji smiercë zaradzy” 'swojej śmierci zaradzi' („,iscënk I”). Znaczenie użytej w pierwowzorze frazy zostaje w przekładzie utrzymane, jednakże tłumacz całkowicie wyeliminował z przekładu frazeologizm.

Opisową metodę translacji wykorzystał również Tomasz Fopke, tłumacząc na język kaszubski wiersze Jana Brzechwy, które zostały opublikowane w zbiorze Brzechwa dzecoma (Brzechwa 2014). U Fopkego przykładów poszukiwania na gruncie tradycji kaszubskiej ekwiwalentnych związków frazeologicznych do tych, które zostały użyte w pierwowzorze, właściwie nie odnotowano.

Opisowa wykładnia związku frazeologicznego pojawiła się w translacji utworu Zebra. W polskojęzycznym pierwowzorze tego wiersza Brzechwy znalazło się wyrażenie frazeologiczne $z$ bożej łaski, odnotowane w następującym kontekście „Czy też malarz z bożej łaski / Pomalował osła w paski?”. Frazeologizm $z$ bożej łaski może być interpretowany dwojako: w pierwszym rozumieniu odnosi się on do osoby utalentowanej, mającej wybitne zdolności i wrodzone predyspozycje do wykonywania czegoś, $w$ drugim znaczeniu to samo wyrażenie może zostać użyte ironicznie i wówczas odnosi się do kogoś 
mało zdolnego i nieutalentowanego (Bąba, Liberek 2003:357). W wierszu Brzechwy skłanialibyśmy się przyjąć raczej to drugie rozumienie omawianego tu frazeologizmu - wspomniany w utworze polskiego poety malarz $z$ bożej łaski to malarz marny, bez zdolności. Tłumacz wyeliminował frazeologizm w przekładzie i opisowo wyłożył treść omawianego tu wyrażenia: „Czë téż malôrz nié za dobri / W sztrépczi òsła pòmalowôł?”.

Obecny w pierwowzorze wiersza Kaczka dziwaczka związek frazeologiczny A niech to gęś kopnie właściwie zupełnie nie został przetłumaczony. Tłumacz najpewniej nie znalazł dla niego ekwiwalentu w kaszubszczyźnie, ale zarazem nie starał się dać opisowej wykładni struktury frazeologicznej. Omawiając przekład tego frazeologizmu, należałoby podczas analizy uwzględnić też wers poprzedni, ponieważ w translacji oba wersy tworzą jedno spójne wypowiedzenie: „Gryzły się kaczki okropnie : / A niech tę kaczkę gęś kopnie”. W pierwowzorze polskim kaczki gryzą się, tzn. kłopoczą zachowaniem kaczki-dziwaczki, ale z poczucia bezradności stwierdzają: „A niech tę kaczke gęś kopnie"', czyli oświadczają, że nie obchodzi ich ta cała sytuacja i zachowanie. Natomiast w tłumaczeniu kaszubskim kaczki nie mogą pojąć, jak to możliwe, że kaczka może tak dziwaczeć. W kaszubskojęzycznej wersji utworu powyższe dwa wersy zostały przełożone za pomocą następujących słów: „Nie miesca sã kaczkóm w głowie: / Jak mòże kaczka tak sowiec?!”. Jak widać, mamy tu do czynienia z dość swobodnym przekładem, dla polskiego frazeologizmu tłumacz nie znalazł ekwiwalentu, ale posłużył się metodą kompensacji: mianowicie związek frazeologiczny w kaszubskiej translacji pojawia się w wersie wcześniejszym jako odpowiednik słów, które w pierwowzorze nie miały charakteru frazeologizmu. Zwrot nie miescëc sã $w$ głowie, mający też polski odpowiednik 'nie mieścić się w głowie', nie jest tożsamy z znaczeniem czasownika gryźć się, który oprócz podstawowego znaczenia 'rozrywać za pomocą zębów samego siebie' ma też znaczenie metaforyczne: 'martwić się, kłopotać się, trapić się, niepokoić się czymś, przejmować się jakąś sprawą, zadręczać się czymśs. Jeśli mówimy, że coś nie mieści nam się w głowie, mamy na myśli to, że coś przekracza nasze możliwości rozumienia, wyobrażenia, coś jest dla nas zadziwiające, skutkiem tego może być fakt, że się martwimy, kłopoczemy, jednakże ów skutek nie jest równoznaczny z przyczyną.

Przykład przetłumaczenia przez Tomasza Fopkego użytego w pierwowzorze frazeologizmu za pomocą metaforycznego związku wyrazowego utworzonego przez samego autora tłumaczenia odnajdujemy też $\mathrm{w}$ wierszu Kaczka dziwaczka. W polskim oryginale tego utworu pojawił się zwrot frazeologiczny pisać drobnym maczkiem, odnotowany w następującym kontekście „pisać list drobnym maczkiem”. Fopke nie dość, że w kaszubskim przekładzie 
wprowadził nowe nieznane kaszubszczyźnie połączenie wyrazów, to dokonał także modyfikacji znaczenia związku frazeologicznego występującego $\mathrm{w}$ pierwowzorze. Użyty w oryginalnym polskim tekście wiersza Brzechwy frazeologizm pisać coś drobnym maczkiem ma znaczenie: 'pisać coś niewielkimi, drobnymi literami'. Tymczasem w przekładzie Fopkego odnajdujemy następujące tłumaczenie przywołanych wyżej słów: „sëpnąc w lëst réżkã lëtrów” („Dzywnisa-kaczka”). Zwrot ten - nienotowany w słownikach kaszubszczyzny jako frazeologizm - w dosłownym przekładzie na język polski miałaby brzmienie 'sypnąć w list szereg liter'. Użycie tej autorskiej metafory, pociągającej za sobą modyfikację znaczenia, motywowane było najpewniej dążeniem do przynajmniej częściowego odzwierciedlenia znaczenia oryginału przy jednoczesnym utrzymaniu rymów i rytmiki w wierszu.

W polskojęzycznym wierszu Julina Tuwima zatytułowanym Lokomotywa (Tuwim 2013) pojawiło się wyrażenie jak żólw mające charakter frazeologizmu, odnotowane w następującym kontekście: „Najpierw powoli jak żółw - ociężale". Lokomotywa porusza się jak żółw, czyli bardzo powoli i ociężale (Dubisz, Sobol 2005: 712). W kaszubskojęzycznym przekładzie tego utworu, przenośne wyrażenie jak żółw zostało zastąpione wyrażeniem, również utrzymującym przenośne znaczenie. Cały wers w kaszubskiej translacji ma następujące brzmienie: „Nôprzód - pòmału - jak zwiérz z cãżką czedą” („Lokòmòtiwa”). Lokomotywa w kaszubskim przekładzie porusza się „jak zwiérz z cãżką czedą" - 'jak zwierz z ciężkim łańcuchem. Łańcuch uniemożliwia zwierzęciu szybkie i sprawne poruszanie się, stąd też idzie ono również powoli i ociężale, podobnie jak żółw. To nowe połączenie wyrazów zostało wprowadzone do utworu przez Tomasza Fopkego przede wszystkim po to, aby utrzymać rym oraz rytmikę, a jednocześnie oddać sens oryginału, nie zatracając przy tym występującego w pierwowzorze przenośnego znaczenia.

Jak pokazuje powyższa analiza, tłumacze tekstów literackich z języka polskiego na język kaszubski w różny sposób starają się dokonywać translacji frazeologizmów. Najczęściej decydują się na opisowe wyłożenie frazeologizmu, zatracając przy tym kontekst kulturowy. Czasami tworzą konstrukcje okazjonalne, które także nie są zakorzenione w żadnej kulturze. Konstruowanie własnych połączeń wyrazowych, które w mniemaniu autorów tłumaczeń mają mieć charakter neofrazeologizów, wynika stąd, iż kaszubszczyzna jest językiem wciąż podlegającym procesowi rozwoju, niezupełnie ukształtowanym. W sytuacji, gdy autorom kaszubskojęzycznych tekstów brakuje odpowiednich słów w zasobach kaszubszczyzny, istnieje tendencja do tworzenia zgodnie z regułami słowotwórczymi języka neologizmów - najpewniej tłumacze analogicznie potraktowali frazeologizmy. Uznali, iż skoro w ka- 
szubszczyźnie brakuje ekwiwalentnego związku frazeologicznego, to można utworzyć okazjonalizm frazeologiczny. Wydaje się jednak, że taki sposób tłumaczenia związków frazeologicznych nie zawsze jest najlepszy, jako że te połączenia wyrazowe są nieraz niezrozumiałe dla czytelnika; ponadto budzi wątpliwość, czy można stosować w stosunku do nich określenie neofrazeologizm. Frazeologizmy z definicji są połączeniami wyrazowymi już utrwalonymi w tradycji, wpisanymi w kulturę. Nie można tego natomiast powiedzieć o metaforycznych związkach wyrazowych utworzonych przez kaszubskich tłumaczy. Choć trzeba zauważyć, że autorzy tłumaczeń czasem starają się znaleźć ekwiwalentny związek frazeologiczny w języku docelowym i wówczas w najpełniejszym zakresie są pośrednikami między dwiema kulturami. Niewątpliwie najlepszym rozwiązaniem translatorskim podczas tłumaczenia związków frazeologicznych jest znalezienie w języku przekładu adekwatnego frazeologizmu, który byłby pełnym ekwiwalentem formy użytej w oryginale, jednak nie zawsze ten postulat da się zrealizować.

Drugą kwestią, którą chciałam omówić w tej pracy, jest problem z tłumaczeniem na kaszubszczyznę tych polskich wyrazów, które odnoszą się do przedmiotów lub zjawisk charakterystycznych dla egzotycznych kultur. Tę trudność napotkał Stanisław Janke podczas przekładu Sonetów krymskich Adama Mickiewicza (Mickiewicz 1998) i stał się pośrednikiem między kulturą muzułmańską i kaszubską. Autor przekładu musiał zająć postawę wobec elementów "trzeciej kultury” i zdecydował się na niewprowadzanie do tekstu docelowego sygnałów związanych z kulturą Wschodu.

W kaszubszczyźnie brakuje wyrazów, które nazywałyby przedmioty czy zjawiska kulturowe właściwe tradycji Wschodu i religii islamskiej. W pierwowzorze sonetu XI Ałuszta $w$ dzień pojawił się rzeczownik namaz, oznaczający muzułmańską rytualną modlitwę, będącą jednym z filarów wiary wyznawcy islamu. Janke zamiast rzeczownika namaz użył wyrazu psalm, który jako pieśń modlitewna jest zakorzeniony w kulturze chrześcijańskiej. Natomiast $\mathrm{w}$ translacji sonetu XVII Ruiny zamku w Bałakławie motyw namazu w kaszubskiej wersji został wyeliminowany na rzecz metaforycznego wyrażenia mòdlëtewnô deka 'modlitewny koc'.

Muzułmański koloryt religijny usunięto także z kaszubskiego przekładu sonetu Bakczysaraj w nocy. W wierszu tym pojawił się rzeczownik izan, oznaczający nawoływanie do modlitwy przez muezzina - specjalnie wytypowanego mężczyzny, który w kulturze islamskiej pięć razy dziennie wzywa z minaretu do modlitwy. W kaszubskojęzycznym tłumaczeniu ekwiwalentem tego słowa jest bòżanka, czyli 'pieśń nabożna, religijna, śpiewana przez chrześcijan, którą przeciwstawia się pieśni świeckiej - kòzance’ (Sychta 1965-1976, 
I: 52). W tym samym sonecie w pierwowzorze została odnotowana nazwa menar, czyli minaret - jest to wieża stawiana przy meczecie, $\mathrm{z}$ której muezin zwołuje wiernych islamskich na modlitwę (Bielawski, red. 1971: 371; Danecki 1997-1998, I: 134; Marek, Nalborczyk 2005: 195; Sobol 1995: 724). W kaszubskojęzycznej translacji także ten wyraz został wyeliminowany i zastąpiony nazwą wieża. W polskim pierwowzorze jest mowa o tym, że cień pada z menaru i wierzchu cyprysa: „Tu cień pada z menaru i wierzchu cyprysa”, w kaszubskojęzycznym przekładzie mamy do czynienia z cieniem padającym z wieży i wierzchu cyprysa: „Tuwò céń sygô $\mathrm{z}$ wieżë ë wiérzkù cyprysa”.

W sonetach XI Ałusza w dzień i V Widok gór ze stepów Kozłowa został użyty rzeczownik chylat, oznaczający w Turcji osmańskiej oraz w dawnej Persji honorową szatę, którą władca kraju lub dostojnik ofiarowywał osobom zasłużonym (Sobol 1995: 181). W obu powyższych sonetach Janke wyeliminował właściwy dla kultury Wschodu egzotyzm chylat, zastępując go wyrazem sëknia 'suknia'. Innym elementem ubioru, którego nazwy tłumacz kaszubski pozbył się z sonetu V Widok gór ze stepów Kozłowa oraz z sonetu IX Mogity haremu, jest turban, czyli tradycyjne arabskie nakrycie głowy, zawijane ręcznie $\mathrm{z}$ długiego pasa tkaniny bawełnianej, noszone przez mężczyzn w krajach muzułmańskich i Indiach (Sobol 1995: 1136). W sonecie V turban pojawił się jako atrybut Mirzy - muzułmańskiego przewodnika; Janke w translacji tego utworu nazwę turban zastąpił rzeczownikiem $c z o ̂ p k$, który na język polski należy tłumaczyć jako 'kapelusz'. Mirza w kaszubskojęzycznym wierszu mówi o gwieździe znajdującej się nie nad jego turbanem, ale kapeluszem.

Natomiast z sonetu XIII wyeliminował tłumacz wyrazy drogman i giaur. Ten pierwszy rzeczownik odnosi się do tłumacza będącego pośrednikiem między mieszkańcami Bliskiego Wschodu a cudzoziemcami. Drogman nie tylko pośredniczył w komunikacji językowej, ale też często pełnił funkcję dyplomaty $\mathrm{w}$ relacjach $\mathrm{z}$ krajami chrześcijańskimi. W kaszubskojęzycznym przekładzie zamiast drogmana pojawia się stolem, postać znana w kaszubskiej mitologii jako olbrzym posiadający wielką siłę. Wprowadzenie mitycznego stolema zamiast drogmana ma służyć wpisaniu sonetu Mickiewicza w kulturę kaszubską. Również wyraz giaur, będący muzułmańskim określeniem innowiercy, został wyeliminowany z kaszubskiej translacji i zwrot „czy giaur pali domy” został przetłumaczony jako „czë sztorëm topi bôtë” - 'czy sztorm topi łodzie.' Motyw giaura usunięto także w kaszubskiej translacji sonetu Mogity haremu, gdzie rzeczownik ten został zastąpiony wyrazem cëzyńc - 'człowiek obcy, obcokrajowiec'.

W sonecie XII Ałuszta w nocy wystąpił motyw wschodniej odaliski, czyli białej niewolnicy w haremie sułtana tureckiego. Noc wschodnia jest porów- 
nana do odaliski, która usypia swego pana pieszczotami, a gdy tego morzy sen, ona znowu budzi go do pieszczot. W tłumaczeniu kaszubskim tego wiersza nie pojawia się postać odaliski, a noc wschodnia zostaje porównana do dziewczyny, którą ktoś mani, usypia pieszczotami niczym kochanek wiosną i pobudzony znowu budzi ją do pieszczot. W kaszubskojęzycznej translacji zmienia się podmiot pieszczot - to nie kobieta pieści mężczyznę, lecz mężczyzna kobietę. Takie odwrócenie relacji ma być sposobem wpisania utworu w realia kultury Zachodu, także kultury kaszubskiej, w której to mężczyzna musi dbać i zdobywać kobietę. Pierwowzór sonetu XII odwoływał się do kultury wschodniej, tureckiej, gdzie kobieta jest poddaną i służącą sułtana. Tłumacz kaszubski wyeliminował element egzotyczny ze swojej translacji, przystosowując wiersz do obyczajów obowiązujących w jego rodzimej, kaszubskiej kulturze.

Stanisław Janke, dokonując przekładu Sonetów krymskich na język kaszubski, w stosunku do elementów "trzeciej kultury” zasadniczo stosował strategię adaptacji: dość swobodnie eliminował pierwiastki obce i zastępował je swojskimi. Wyrazy nazywające przedmioty oraz zjawiska związane z niekaszubską i niepolską kulturą zostały wymienione na nazwy bliższe mentalności kaszubskiego czytelnika, motywy muzułmańskie zaś zastąpiono chrześcijańskimi. Adam Mickiewicz starał się osadzić cykl Sonetów krymskich w realiach orientu, świadomie włączając w swój utwór literacki motywy właściwe kulturze wschodniej, natomiast Stanisław Janke w kaszubskim tłumaczeniu niemal konsekwentnie eliminował symbole związane z kulturą Wschodu. Wybraną przez autora przekładu strategią translatorską było usuwanie w tekście docelowym nośników konotacji obcości związanych z „trzecią kulturą”. Szukając w kulturze kaszubskiej substytutów elementów muzułmańskich, tłumacz zburzył pierwotną strukturę tekstu i uniemożliwił czytelnikowi dotarcie do sensów wpisanych w pierwowzór. Poniekąd takie decyzje tłumacza mogą wynikać z niedostatku w kaszubszczyźnie odpowiedniej leksyki, nazywającej przedmioty czy zjawiska właściwe egzotycznym kulturom. Jednakże rozwiązaniem w takiej sytuacji mogło być przyswojenie kaszubszczyźnie obcego słownictwa. Wyeliminowane przez Jankego wyrazy w polszczyźnie też były zwykle pożyczkami z innych języków, nic nie stało na przeszkodzie, aby przyswoić je także systemowi leksykalnemu kaszubskiemu.

Mimo iż autorzy przekładów tekstów literackich z języka polskiego na język kaszubski zakorzenieni są zarówno w kulturze polskiej, jak i kaszubskiej, wydaje się, że można ich nazwać pośrednikami między kulturami. Język i kultura są nieodłączne i wchodzą ze sobą we wzajemne relacje, dlatego też, gdy przekłada się tekst kultury z jednego języka na drugi, zawsze jest się po- 
średnikiem między kulturami. Kaszubszczyźnie obce są polskie frazeologizmy, dlatego autorzy kaszubskich tłumaczeń byli zmuszeni do poszukiwania ich ekwiwalentów w języku docelowym. Ponadto Kaszuby to obszar peryferyjny. W ciągu wieków niezbyt częste były kontakty Kaszubów z muzułmana$\mathrm{mi}$, dlatego kaszubszczyzna nie przyswoiła słownictwa związanego $\mathrm{z}$ kulturą Wschodu. Tłumacz dokonujący przekładu tekstów zakorzenionych w egzotycznych kulturach musi uporać się z kontekstem kulturowym takich dzieł i przyswoić je kulturze oraz mentalności Kaszubów. Rola tłumacza literatury polskiej na język kaszubski nie sprowadza się zatem jedynie do pośredniczenia między językami, jest on bowiem także pośrednikiem między kulturami.

\section{Literatura}

Bąba, S., Liberek, J., 2003, Stownik frazeologiczny wspótczesnej polszczyzny, Warszawa.

Bednarczuk, A., 2002, Kulturowe aspekty przekładu literackiego, Katowice.

Bielawski, J. (red.), 1971, Mały słownik kultury świata arabskiego, Warszawa.

Brzechwa, J., 2014, Brzechwa dzecoma, skaszëbił T. Fópka, Gduńsk.

Danecki, J., 1997-1998, Podstawowe wiadomości o islamie, Warszawa.

Dąmbska-Prokop, U. (red.), 2000, Mała encyklopedia przekładoznawstwa, Częstochowa.

Dubisz, S., Sobol, E. (red.), 2005, Wielki słownik frazeologiczny PWN z przysłowiami, Warszawa.

Gołąbek, E., 2012-2013, Słownik polsko-kaszubski, Gdańsk.

Górski, K., Hrabec, S. (red.), 1962-1983, Słownik języka Adama Mickiewicza, Wrocław.

Kochanowski, J., 2011, Treny. Jiscënczi, dolm. J. Mamelsczi, Gdynia.

Krysztofiak, M., 2011, Translatologiczna teoria i pragmatyka przekładu artystycznego, Poznań.

Kucała, M. (red.), 1994-2012, Słownik polszczyzny Jana Kochanowskiego, Kraków.

Mickiewicz, A., 1998, Krimsczé sonetë, Wejherowo.

Mickiewicz, A., 2010, Pón Tadeùsz to je Östatny najachùnk na Lëtwie: szlacheckô historiô $z$

rokù 1811 i 1812 w dwanôsce knégach wiérszã, skaszëbił S. Janke, Wejrowò, Gduńsk.

Nalborczyk, A. S., 2005, Nie bój się islamu. Leksykon dla dziennikarzy, Warszawa. 
Sobol, E. (red.), 1995, Słownik wyrazów obcych, Warszawa.

Sychta, B., 1965-1976, Słownik gwar kaszubskich na tle kultury ludowej, Wrocław.

Tuwim, J., 2013, Nôsnôżniészé wiérztë dlô dzecy, skaszëbił T. Fópka, Gduńsk.

Urbanek, D., 2002, „Elementy trzeciej kultury w procesie przekładu”, [w:] Przekład. Język. Kultura, R. Lewicki (red.), Lublin.

Wołek-San Sebastian, K., 2011, „Trzecia kultura” a problemy przekładu nowszej literatury chorwackiej, Kraków.

Мокиенко, В. М., 2014, „Переводимое и непереводимое во фразеологии”, [w:] Frazeologia a przekład, W. Chlebda (red.), Opole, s. 11-24.

\section{To what extent the translator of literary texts from Polish to Kashubian acts as an intermediary between these cultures?}

\section{Summary}

Kashubian and Polish cultures are not completely separate from each other. Despite intermingling of these two cultures, it can be argued that the translator of literary texts from Polish to Kashubian is, to a certain extent, a go-between for both cultures, and it will not be a problem - for him or her - to give a name to Polish realities which are known to the Kashubians and the Kashubian language. Cultural elements that might be problematic for a Kashubian translator are phraseological units specific for the Polish culture and realities of exotic cultures described in Polish literary texts.

Keywords: culture, Kashubian language , Polish language, literary translation 